\title{
El uso de las píldoras formativas competenciales como experiencia de innovación docente en el grado de magisterio en educación infantil
}

\author{
Juan Carlos Bustamante, Natalia Larraz Rábanos, Eva Vicente Sánchez, José Carrón \\ Sánchez, José Luis Antoñanzas Laborda y Carlos Salavera Bordás. Universidad de Zaragoza
}

Recepción: 29 de julio de 2016 | Revisión: 6 de septiembre de 2016 | Aceptado: 17 octubre de 2016

Correspondencia: Juan Carlos Bustamente | Orcid ID: 0000-0002-8201-0469| Email: jbustama@unizar.es

Citar: Bustamante, JC., Larraz, N., Vicente, E, Carrón, J., Antoñanzas, JL. y Salavera, C. (2016). El uso de las píldoras formativas competenciales como experiencia de innovación docente en el grado de magisterio en educación infantil. ReiDoCrea, 5, $223-234$.

\begin{abstract}
Resumen: Aproximar el aprendizaje basado en competencias al alumnado lleva a que la experiencia docente deba nutrirse de propuestas innovadoras que faciliten dicha tarea. Las Píldoras Formativas Competenciales (PILFORCOMS) son vídeos de corta duración en los que el locutor demuestra de manera breve una competencia relacionada con un contenido teórico, y pueden acercar al alumnado a un papel activo en la construcción de su propio aprendizaje y profesionalización. Objetivos: analizar la viabilidad del uso de este novedoso recurso formativo con estudiantes de Magisterio. Método: con el desarrollo de un proyecto de innovación docente basado en la creación por parte de los alumnos de las PILFORCOMS como actividad práctica evaluable de la asignatura, se recogieron con escalas tipo likert antes y después de la realización del proyecto las percepciones de los estudiantes en relación a la propuesta. Resultados: mostraron que la experiencia ha sido positiva y el planteamiento motivador y útil para promover buenas expectativas de resultado y un aprendizaje eficaz. Conclusiones: la inclusión de una herramienta formativa novedosa como esta permite que, con la tutorización del profesor, el alumnado pueda construir su propio proceso de aprendizaje facilitando una formación en competencias ajustada a los resultados de aprendizaje previstos.
\end{abstract}

Palabras clave: Innovación educativa | Competencia

Use of "the formative pills in competences" as an experience of educational innovation in the early childhood education degree

Abstract: The approaching of the competence-based learning to undergraduate students leads teaching experience to take into account innovative proposals to facilitate the task. The Formative Pills in Competences are short videos where the students show a competence related with a theoretical content adopting an active role to build their own learning and professionalization. Objectives: we aimed to analyze the viability of using this new educational resource in the early childhood education degree. Method: with the development of an educational innovation project based on the elaboration of the Formative Pills in Competences as a subject-related task, we obtained measures before and after the experience to determine the students' perception using a Likert scale. Results: showed that the experience was positive and the proposal was useful and motivating to promote good results expectations and an effective learning. Conclusions: the inclusion of this kind of tools allows students, with professor mentoring, to build their own learning process leading to a competence training adjusted to learning outcome.

Key words: Educational innovation | Competence

Financiación y agradecimientos: El proyecto ha sido financiado por la Universidad de Zaragoza y se ha realizado en el marco de la Convocatoria de Proyectos de Innovación Docente para grupos de profesores 2015/2016 (PIIDUZ_15_043).

\section{Introducción}

El proceso de adaptación al nuevo Espacio de Educación Superior Europeo (EEES) en estos últimos años ha llevado a situar la formación competencial como la premisa clave del proceso educativo y profesionalizante de nuestro alumnado. La necesidad de ofrecer al alumnado oportunidades fehacientes que le permitan acercarse de manera realista al mundo laboral han situado el rol del profesor en ser un buscador incansable de medios, herramientas y recursos que pueda ofrecer a los estudiantes para el desarrollo de sus competencias. La finalidad es conseguir que el propio alumnado sea el que construya su propio proceso de aprendizaje mediante la profundización y el ajuste de los contenidos de aprendizaje a sus características personales (y posibilidades/recursos), de manera que alcancen de este modo los resultados de aprendizaje y las competencias necesarias para llevar a cabo las tareas relacionadas con su futura profesión (sean más competentes). Por tanto, esta realidad implica no solamente un cambio en el currículum y en las tareas académicas, sino también un 
cambio en las estrategias metodológicas utilizadas en nuestras universidades (León, González, López y López, 2012).

Uno de los recursos formativos innovadores que puede emplear el profesorado para promover el desarrollo y la adquisición de competencias en el aula es el uso de las "Píldoras Educativas". Las píldoras educativas consisten en materiales audiovisuales breves (de entre 5-10 minutos) en las que el locutor hace una explicación de un concepto concreto que permita aclarar o complementar los conocimientos o contenidos impartidos en relación a dicho tema (Universidad de Vigo, s.f).

Tomando como referencia las ideas básicas inherentes a este recurso educativo, en esta propuesta se plantea modificar y complementar dicho recurso de manera innovadora (dando un salto o cambio de enfoque) planteando la utilización de píldoras educativas como herramienta orientada a dar la oportunidad a los alumnos para formarse en competencias generales, específicas y/o transversales relacionadas con su titulación. Así, se plantea el uso de las que llamaremos las Píldoras Formativas Competenciales (en adelante, PILFORCOMS). Una PILFORCOM se referiría a un video de corta duración en el que el locutor demuestra de manera breve una competencia relacionada con un tema o contenido teórico.

Por lo tanto, a través de esta experiencia de innovación docente buscamos dar respuesta a la necesidad actual que está centrada en el marco de las competencias, en la que el uso de las nuevas tecnologías (píldoras formativas como recurso basado en el uso de medios audiovisuales) se plantea con el objetivo de mejorar el desarrollo competencial de los estudiantes.

\section{Estrategias de enseñanza-aprendizaje en entornos e-learning y multimedia}

El uso de los entornos virtuales de aprendizaje utilizados en la actualidad permite el uso de las tecnologías para fomentar el proceso de aprendizaje. Dorado (2008), señala tres dimensiones fundamentales a la hora de entender los entornos virtuales de aprendizaje: la tecnología, los contenidos y las interacciones y mediaciones entre los distintos agentes o elementos que intervienen en el mismo. Este autor apuesta por incidir en la última dimensión mencionada, ya que considera que tanto la tecnología como los contenidos de aprendizaje deben estar al servicio de los procesos de aprendizaje y de las interacciones que se producen gracias al mismo. Para ello, propone un modelo centrado en los usuarios y por tanto, centrado en las metodologías y las estrategias de enseñanza y aprendizaje empleadas. En este sentido, Dorado (2008) ahonda en la propuesta del uso de las estrategias y estilos de aprendizaje aplicados en entornos tecnológicos. Así, una herramienta online de aprendizaje debe fomentar la adaptabilidad a los distintos estilos de aprendizaje del alumnado y fomentar el uso de estrategias cognitivas y metacognitivas de aprendizaje para que dicho entorno virtual logre un aprendizaje eficaz en el alumnado.

Mayer y colaboradores identificaron en los años noventa el denominado aprendizaje multimedia (Moreno y Mayer, 1999; Mayer, 2001, 2002), en el cual el estudiante participaría de tres procesos cognitivos: selección, organización e integración (Mayer, 2010). La teoría cognitiva del aprendizaje multimedia (CTML) se ha centrado en la idea de que los aprendices tratan de construir conexiones con sentido entre las palabras y las imágenes y que las personas aprenden más profundamente que aquellos que solamente tienen palabras o imágenes por separado (Mayer, 2001). De acuerdo a esta teoría, una de las principales metas de la instrucción multimedia es animar al aprendiz a construir una conexión mental coherente del material presentado, de este modo el trabajo del aprendiz es dar sentido al material como un participante activo, lo que le 
llevará a construir nuevos aprendizajes (Sorden, 2013). Dichos autores se han basado en una serie de experimentos que han desembocado en cómo el aprendizaje multimedia puede ayudar a los estudiantes a comprender contenidos científicos. Los cinco principios multimedia son los siguientes (Mayer, 2001):

- Multimedia: el aprendizaje es mayor si se usan palabras e imágenes más que únicamente palabras.

- Contigüidad: el aprendizaje es mejorado cuando las imágenes y palabras relacionadas están presentes en el mismo tiempo o al lado de la otra en la pantalla;

- Modalidad: la palabra hablada es mejor que el texto impreso para explicar imágenes.

- Señalamiento: el material de aprendizaje debe estar organizado con encabezamientos claros y contornos claros.

- Personalización: un estilo conversacional es mejor que un estilo formal para el aprendizaje.

\section{El uso de las píldoras en la enseñanza superior}

Las píldoras formativas también denominadas tutoriales audiovisuales de corta duración, son pequeñas piezas de material didáctico de contenido audiovisual diseñado para complementar las estrategias tradicionales de formación y facilitar la comprensión de algunos aspectos de la materia curricular. Pueden estar orientadas a cubrir determinadas lagunas conceptuales, procedimentales y actitudinales $y$, utilizadas adecuadamente, pueden motivar al alumnado en el proceso de enseñanzaaprendizaje. Dichas píldoras permiten ser consultadas y almacenadas y constituyen un recurso formativo de gran atractivo para los estudiantes ya que están ampliamente familiarizados con este tipo de formato similar al de YouTube (Bengochea y Medina, 2013).

Los vídeos de corta duración o píldoras formativas, han estado presentes entre los materiales educativos usados en cursos de todos los niveles en el aula y en la educación a distancia durante las dos últimas décadas y se están utilizando sobre todo en los cursos denominados MOOCs (Massive Open Online Courses) (Whatlley y Ahmad, 2007; Bengochea y Medina, 2013).

Una de las ventajas de las píldoras formativas consiste en que pueden ser realizadas de forma autónoma por el profesorado y el alumnado, utilizando un equipamiento informático básico, aplicaciones asequibles y fáciles de utilizar.

Además el material visual tiene muchas otras ventajas sobre el aprendizaje. Shepard y Cooper (1982) han indicado que el uso de este tipo de material ayuda a crear imágenes durante el aprendizaje y esto es crítico para el proceso memorístico. De este modo, el vídeo como un medio educativo puede proveer descripciones vivas para articular información tácita y un conocimiento difícil de adquirir a través de textos 0 verbalmente (Goodyear y Steeples, 1998).

Young y Asensio (2002) indican que actualmente se están buscando nuevos maneras de utilizar el vídeo de un modo más imaginativo, de tal modo que sea pedagógico y ayude a los estudiantes a alcanzar resultados de aprendizaje, más allá de utilizar el vídeo como una herramienta de presentación, sino como una herramienta de aprendizaje compartido. Estos autores sugieren un modelo de 3I: Imagen, Interacción e Integración. Estas ideas transmiten la necesidad de que los estudiantes sean capaces de interactuar con las imágenes, así como que el vídeo se pueda distribuir de 
manera accesible a todos los estudiantes mediante algún tipo de tecnología. También es deseable que el vídeo se pueda iniciar y parar cuando se desee, de tal modo que se dé la oportunidad a los estudiantes de acceder y controlar su proceso de aprendizaje. Por último, Whatlley y Ahmad (2007) recomiendan que la calidad de la grabación sea la mejor posible, usando los mejores equipamientos que permitan una buena grabación de luz y sonido, así como que la tecnología sea robusta, de tal modo que no se interrumpa la transmisión del vídeo.

Según Bengochea y Medina (2013) a la hora de diseñar y producir una píldora formativa deben tenerse en cuenta una serie de normas a seguir, tanto en el plano didáctico, como en el plano técnico. Se trata de conseguir que sean útiles, amenas y multiplataforma e incluyen las siguientes recomendaciones para su aplicación en el aula: a) planificar y elaborar un script de la secuencia de imágenes, el texto, la voz y los gestos del presentador antes de la grabación; b) elegir el formato más adecuado para el contenido que se va a tratar (busto parlante, diapositivas, animaciones, acciones en pantalla, etc. o una combinación de ellos); c) describir al comienzo los objetivos de aprendizaje; d) conectar cada pieza nueva de información con la previa sincronizando las imágenes, el texto y el sonido; e) usar un lenguaje sencillo y claro y una voz activa; f) enfocar el contenido de un concepto de forma clara y objetiva, eliminando todo el material no esencial; g) centrar la atención en las áreas significativas de la pantalla; $h$ ) incluir algún cuestionario o algunas preguntas de autoevaluación al final del video con las soluciones como texto en otra parte y, i) no incluir como texto escrito en el video toda la narración de audio sino incluirlo como subtítulos.

Las investigaciones existentes en relación al uso de las píldoras formativas muestran validez pedagógica en relación a los aprendizajes adquiridos y sugieren el uso de estas herramientas como elemento mediador de aprendizaje. Por ejemplo, Estévez y González (2014) han llevado a cabo un estudio cuasi-experimental con estudiantes de la Universidad de la Laguna en el que, por un lado, han validado el uso de las píldoras formativas en el profesorado que ha llevado a cabo la experiencia, observando un alto grado de aceptación sobre la estructura del material didáctico audiovisual y, por otro lado, muestran la validez pedagógica de la píldora audiovisual como material didáctico frente al material impreso, observando una mejora en la calificación media superior en el grupo experimental frente al grupo control. Concluyen que las píldoras de conocimiento audiovisuales tienen mayor impacto didáctico frente a los apuntes tradicionales impresos o su equivalente en documento PDF estático de solo lectura. En otro estudio, Delgado y Ruiz (2014) presentan una experiencia educativa llevada a cabo en la Universidad de Burgos a través de la creación de píldoras educativas por parte de su alumnado con fines pedagógicos, obteniendo resultados satisfactorios en el alumnado sobre dicha utilización.

En los resultados preliminares de las investigaciones revisadas por Whatlley y Ahmad (2007) realizadas con estudiantes de la Universidad de Manchester en el que se utiliza el vídeo como una herramienta para resumir los contenidos de las asignaturas, han observado que los estudiantes encuentran dichos vídeos muy útiles para estudiar el material de las asignaturas así como para repaso.

En aprendizaje no formal, también se han utilizado las píldoras formativas, o knowledge pills como una metodología innovadora para la formación de trabajadores de pequeñas y medianas empresas, formadores y consultores (Carrera, 2011, 2012). Este proyecto, financiado por la Unión Europea a través del Programa de Aprendizaje Permanente, está basado en la aplicación de la Metodología de Píldoras de Conocimiento de distintos formatos (audio, vídeo y presentación multimedia) durante 
siete años mediante la colaboración de distintos países socios. El objetivo era crear una plataforma virtual para compartir conocimiento explícito y tácito entre las distintas empresas y, a su vez, mostrar casos exitosos de su aplicación en distintas organizaciones. Este ejemplo es una clara apuesta desde la educación no formal para la adquisición de competencias profesionales de los trabajadores a través de una metodología innovadora como son las píldoras formativas. Los resultados que se muestran en el informe son claramente satisfactorios en relación al uso y el aprendizaje de competencias de los trabajadores de los casos expuestos.

Sin embargo, al ser una herramienta muy novedosa, no existen suficientes estudios del uso de este recurso educativo como para validar su utilización en el aula universitaria de forma generalizada. Por este motivo, a través de nuevas experiencias se puede investigar y observar los resultados de aprendizaje en el alumnado universitario. En este caso, estamos de acuerdo con Schnotz (2002) en que el aprendizaje multimedia podrá tener éxito generalizado si su uso se guía por una teoría cognitiva basada en la investigación empírica. Para este autor, los modelos de aprendizaje multimedia son un primer paso hacia la comprensión teórica del aprendizaje, pero sería necesaria mayor investigación para entender la relación entre la representación interna y externa del conocimiento y el papel que tiene la memoria de trabajo asociada a las distintas modalidades sensoriales. A su vez considera que es necesario conocer el efecto de las estrategias de aprendizaje metacognitivo y el aprendizaje autodirigido a partir de las representaciones múltiples que presenta este tipo de conocimiento, así como el tipo de ayuda que debe proporcionarse a los estudiantes además de los aspectos motivacionales relacionados con el aprendizaje.

Por tanto, el objetivo general de este trabajo ha sido proponer, analizar y valorar el uso de un recurso educativo novedoso como es la píldora formativa competencial, con el fin de que se adapte al contexto de la educación universitaria de aprendizaje basado en competencias y que responda a la sociedad de la información y comunicación en la que se enmarcan los procesos de enseñanza-aprendizaje. Así, se busca evaluar y valorar la idoneidad del recurso y la opinión y satisfacción del alumnado ante el uso de las píldoras formativas competenciales como experiencia ligada al aprendizaje competencial.

\section{Método}

\section{Participantes}

La puesta en marcha de la experiencia se llevó a cabo con alumnado de primer curso del Grado de Magisterio en Educación Infantil de la Universidad de Zaragoza durante el segundo semestre del curso educativo 2015-16 en la asignatura de Psicología del Desarrollo II. Participaron 65 estudiantes del grupo de mañanas y 52 estudiantes del grupo de tarde.

\section{Instrumentos}

Para la recogida de datos, se realizaron dos cuestionarios ad hoc de forma telemática que permitieron medir en dos momentos diferenciados las percepciones y perspectivas de los estudiantes. Así, una vez los estudiantes fueron introducidos en las premisas e instrucciones relacionadas con el desarrollo del proyecto, se les instó a que rellenaran un cuestionario previo al inicio del desarrollo de las tareas asociadas al proyecto (medida PRE). De la misma forma, una vez finalizadas todas las tareas relacionadas y durante la última fase de la propuesta, se recogieron unas medidas POST con la 
cumplimentación de un cuestionario adaptado, similar al que se utilizó para la recogida de la medida PRE.

Los cuestionarios se basaron en la construcción de una serie de ítems en los que se valoraba el grado de conocimiento y experiencia en relación a las PILFORCOM y el grado de satisfacción con el recurso utilizado gracias a su aplicación en el aula. Las medidas se basaron en una escala tipo Likert con cuatro opciones de respuesta de menor a mayor acuerdo con la premisa presentada (1, muy en desacuerdo; 2 , en desacuerdo; 3, de acuerdo; 4, muy de acuerdo). El cuestionario inicial constó de 12 ítems (los dos primeros ítems a, diferencia de los diez restantes, recogían datos sobre el conocimiento y experiencia por parte de los estudiantes con este tipo de iniciativas basándose en una escala dicotómica de Sí y No). Por otra parte, el cuestionario final constó de 10 ítems (el ítem 1, a diferencia de los nueve restantes, recogía la valoración de la experiencia por parte del alumnado en una escala constituida por las categorías Muy buena, Buena, Mala y Muy mala).

\section{Procedimiento}

La experiencia se desarrolló como una actividad no presencial en la que los estudiantes debían desarrollar unos materiales audiovisuales de breve duración en los que demostraran competencias específicas asociadas con cada uno de los temas tratados en la asignatura, para que sirviera al resto de compañeros como muestras de aproximaciones competenciales útiles para su futuro profesional. En este sentido, los estudiantes fueron los constructores de su propio aprendizaje estando directamente relacionados con la elaboración del material formativo, o utilizándolo como medio complementario de formación. Para ello se instó a los estudiantes a crear pares de trabajo. Así, contábamos con 31 grupos (uno de los grupos finalmente fue conformado por 3 personas) en el grupo de docencia de mañanas y 26 grupos en el grupo de docencia de tarde.

\section{Actividades realizadas}

Para el desarrollo del proyecto fue necesaria la realización de algunas tareas por parte del equipo de trabajo con el fin de dar cierta entidad e infraestructura al proyecto y facilitar la consecución de los objetivos planteados. En este sentido, las tareas llevadas a cabo por parte del equipo fueron las siguientes:

- Elaboración de un dossier explicativo: se confeccionó un dossier en el que se explicaban las directrices y puntos clave a nivel conceptual y procedimental para dicha tarea. En el mismo se contextualiza al alumnado en las premisas didácticas de la que parte la idea, así como se explicita el concepto de PILFORCOM; dando así la opción al alumnado de que pudiera entender el sentido educativo de este tipo de propuestas.

- Construcción de una plataforma virtual en forma de página web, gracias a la tecnología Google Sites, que sirviera como medio para centralizar la publicación de las píldoras y dar la posibilidad al alumnado de tener un punto de encuentro en el que pudieran solventar dudas, realizar comentarios y manejar o consultar información útil referida a la elaboración de las píldoras.

- Elaboración de un vídeo explicativo que permitiera al estudiante contar con un material audiovisual de apoyo que le permitiera entender con mayor claridad el contenido del documento explicativo antes presentado.

- Apoyo, seguimiento y tutorización de la elaboración de las PILFORCOMS. Para ello se realizó una sesión explicativa al inicio del semestre que permitiera al alumnado conocer de manera concreta todos los aspectos de interés 
relacionados con la realización de la tarea, y pudieran resolver todas las dudas que surgieran así como realizar los comentarios (e incluso sugerencias) que creyeran conveniente. Además, se instó al alumnado a realizar un seguimiento en la confección del material en cuestión. Para ello se les indicó que era necesario recibir feedback por parte del profesorado antes de publicar el producto final de cada una de las píldoras.

- Evaluación y valoración de las píldoras entregadas. Para esta tarea se tuvieron en cuenta la adecuación del contenido de la píldora a la competencia específica (CE) en cuestión trabajada, la concreción y el nivel de especificidad teórico-práctica de la conclusión extraída, el grado de adecuación con respecto a la identificación de los aspectos teóricos más relevantes en relación a la píldora creada, el ajuste del producto elaborado a las directrices planteadas, la originalidad del trabajo y la participación en el comentario crítico de otras píldoras.

Por otra parte, se planteó que el sistema de distribución de píldoras a realizar por los distintos grupos de trabajo se basara en la premisa de que los grupos pares debían realizar las píldoras correspondientes a los temas pares y los grupos impares debían realizar las píldoras correspondientes a los temas impares. Así, y teniendo en cuenta que la asignatura cuenta con cinco temas y el primero de ellos tiene una clara naturaleza introductoria, se realizaron píldoras para cuatro temas. De esta forma, cada pareja debía realizar dos PILFORCOMS a lo largo del semestre. Específicamente, las tareas a realizar por el alumnado fueron las siguientes:

- Profundizar en los contenidos del tema correspondiente.

- Diseñar un boceto de la propuesta para la píldora formativa. Los estudiantes debían ajustar y concretar la línea del discurso, así como su contenido y la duración de la píldora. Debían preparar un guion concreto en el que se especificara cada elemento que formaría parte de la intervención, teniendo en cuenta los siguientes aspectos:

- Presentación: saludo y presentación del grupo de trabajo que había intervenido. Determinando (si procedía) el permiso por parte de los cuidadores legales, en caso de que se procediera a la grabación de un menor de edad.

- Objetivo de la píldora: QUÉ se buscaba con la demostración.

- Competencia Específica abordada en la píldora: se trataba de competencias específicas relacionadas con la asignatura y que se recogían en la guía docente de la misma.

- Demostración de la competencia.

- Conclusión breve en relación a la demostración (de una o dos frases).

- Identificación y enumeración de aspectos teóricos a considerar.

- Saludo de despedida: agradecimiento por la atención del público.

- Diseñar los materiales y recursos necesarios para la grabación de su píldora. Los alumnos debían hacer demostraciones sencillas, claras y realistas. Preparar situaciones cercanas a la realidad o contexto con el que se relacionara la competencia. Crear una atmosfera adecuada para el video y el contenido que se deseaba presentar. También se les facilitó directrices en relación al cuidado de la indumentaria de las personas que intervinieran en el vídeo, el cuidado del discurso y la narración y el cuidado de aspectos visuales del vídeo.

- Gestionar la grabación y maquetación de su píldora formativa. Los estudiantes debían elegir el software o aplicación informática que más se ajustara a sus intereses y posibilidades para la preparación, elaboración y edición de la píldora. Algunas propuestas se hicieron llegar desde el equipo de trabajo en relación a programas de gestión de imágenes y videos (Windows Movie Maker, 
VideoPad Editor, etc.), y programas de captura de imagen (Debut Video Capture, Active Presenter, etc.).

- Una vez la píldora era elaborada se debía proceder a facilitar la visualización del vídeo al resto de compañeros.

\section{Análisis de datos}

Se analizaron a nivel descriptivo los datos obtenidos de la experiencia educativa en relación a las respuestas obtenidas de los cuestionarios inicial y final, con el fin de realizar una comparativa entre las actitudes y percepciones de los estudiantes antes y después de la puesta en marcha del proyecto en aspectos relacionados con el grado de interés, utilidad y aplicabilidad (idoneidad), viabilidad y satisfacción, así como recoger datos sobre las expectativas creadas por los estudiantes ante la realización de una iniciativa formativa como esta. Dicho análisis pretende mostrar unos resultados que ofrecieran una evidencia ajustada a la propia evolución de la propuesta a lo largo del tiempo con el fin de discernir de forma más clara el alcance real de la misma.

\section{Resultados}

Es importante considerar como punto de partida que son pocos los alumnos que eran conocedores del concepto de píldora educativa (un $23.7 \%$ de la muestra, ver figura 1), siendo muy bajo el porcentaje de alumnos que había tenido algún tipo de experiencia previa con la realización de este tipo de material audiovisual (solo un $9.2 \%$ de la muestra, ver figura 2). Es interesante destacar que un elevado porcentaje de estudiantes estaba de acuerdo o muy de acuerdo, antes de iniciar el proceso de elaboración de las píldoras, con el hecho de que la ayuda del profesor sería clave para el desarrollo de las PILFORCOMS (un 98.6\%). Estos datos podrían hacernos entrever que el proceso de tutoría y seguimiento por parte del profesorado puede ser clave para el éxito de este tipo de iniciativa. De hecho, parece confirmarse la importancia de la tutorización, teniendo en cuenta que al finalizar el proyecto la mayor parte de los estudiantes seguía considerando importante dicha ayuda para la tarea en cuestión (un $97.3 \%)$.

Por otra parte, dado que considerábamos determinante que el alumno percibiera el alcance didáctico de las PILFORCOMS, era necesario valorar el grado de interés suscitado por esta propuesta. Los resultados muestran que los estudiantes parecen estar de acuerdo o muy de acuerdo con respecto al interés de este tipo de tarea (un $93.4 \%$ de la muestra), viéndose incrementado aún más dicho grado de acuerdo una vez han conocido este tipo material y se han visto implicados en este proyecto. De hecho, observamos que el porcentaje de respuestas a la puntuación 4 (muy de acuerdo) se ve incrementado en la medida POST (pasando de un 30,7\% a un 48,6\%). Por otra parte, el porcentaje de respuestas a la puntuación 3 (de acuerdo) se ve reducido en la medida POST (de un $62.7 \%$ a un $45.8 \%$ ). Estos datos corroboran las posibilidades que tiene el uso de este tipo de recursos, dada su buena aceptación inicial por parte de los estudiantes y confirmándose su interés también al finalizar el mismo. De hecho, el alumnado ha mostrado muy buenas expectativas de resultado al indicar que un importante porcentaje de los mismos estaba de acuerdo, o muy de acuerdo, con la afirmación de que los resultados a obtener serían buenos (un 93.3\%) y con la afirmación de que los niveles de aprendizaje serían elevados (un 92\%). Por ello, los datos muestran que la propuesta es claramente percibida cómo útil para la preparación de la asignatura y adquisición de las competencias relacionadas (por un $89.4 \%$ de los estudiantes), y como una forma novedosa y motivadora para afrontar la asignatura (por un $85,3 \%$ de los estudiantes). Así, un $90.2 \%$ de la muestra está de 
acuerdo o muy de acuerdo en que la realización de las PILFORCOMS les ha motivado para afrontar la asignatura y adquirir las competencias relacionadas con la misma.

Siguiendo en la misma línea, todos los estudiantes coinciden en que la experiencia con la realización de las PILFORCOMS ha sido buena o muy buena (ver figura 3), obteniendo que un $93.1 \%$ ha mostrado estar de acuerdo o muy de acuerdo con el hecho de que han aprendido mucho con la realización de este tipo de material. De esta manera, estos resultados podrían apoyar que iniciativas novedosas como estas, que requieren de procesos de transferencia del contenido de los temas tratados en la asignatura al contexto real, pueden fomentar un tipo de aprendizaje significativo. Esto podría hacernos pensar que a pesar de la dificultad y el esfuerzo que ha supuesto para el alumnado su realización, ha servido para identificar y demostrar de una forma adecuada una competencia específica relacionada con la asignatura y a su vez, profundizar de manera crítica y constructiva en los contenidos de la misma; no siendo únicamente importante el hecho de trabajar e interiorizar los aspectos teóricos relacionados. En efecto, los resultados muestran que un $41.7 \%$ de los estudiantes han considerado que identificar los aspectos teóricos relacionados con la competencia no ha sido lo más complicado en la elaboración de las píldoras. Siendo lo más complicado, para un $79.1 \%$ de los estudiantes, el identificar la manera más adecuada de demostrar una competencia específica.

Finalmente, favorecer el uso de los medios audiovisuales y las TICs es un componente que ha optimizado el alcance de este tipo de propuestas. En sí, casi la mitad de los estudiantes antes de la puesta en marcha del proyecto no consideraban un problema el tener en cuenta los aspectos técnicos relacionados con el montaje y elaboración de las PILFORCOMS (un 46.7\%), lo que puede llevarnos a considerar que los conocimientos de los estudiantes en el uso de este tipo recursos puede propiciar de forma más clara la llegada de este tipo de propuestas a las aulas. Un aspecto que se ve corroborado al finalizar el proyecto, cuando el $59.7 \%$ del alumnado confirma que el tener en cuenta los aspectos técnicos no ha sido un problema a la hora de elaborar y montar las PILFORCOMS. Además, el $97.2 \%$ de los estudiantes han considerado que el hecho de crear un plataforma virtual para centralizar la publicación de las píldoras y realizar los comentarios asociados a ellas ha sido útil para organizar este tipo de material didáctico, pudiendo facilitar el estudio de la asignatura. Por tanto, dadas sus posibilidades se ha intentado promover la transmisión de información e ideas concretas y sintetizadas relacionadas con el contenido de la asignatura a través de una página que da acceso al alumnado a dicho material en cualquier lugar y momento (favoreciendo, al mismo tiempo, el aprendizaje ubicuo).

Figura 1. Distribución de respuesta del alumnado a la afirmación "Era conocedor/a del concepto de Píldora Educativa que está relacionado con el concepto de PILFORCOM"

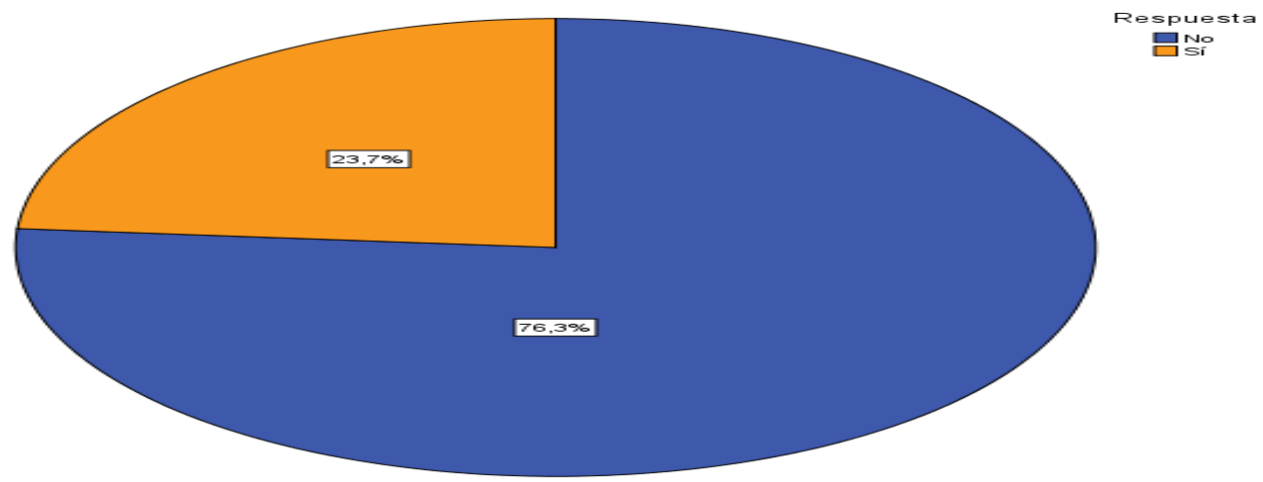


Figura 2. Distribución de respuesta del alumnado a la afirmación "Tengo experiencias previas en la realización de este tipo de material audio-visual"

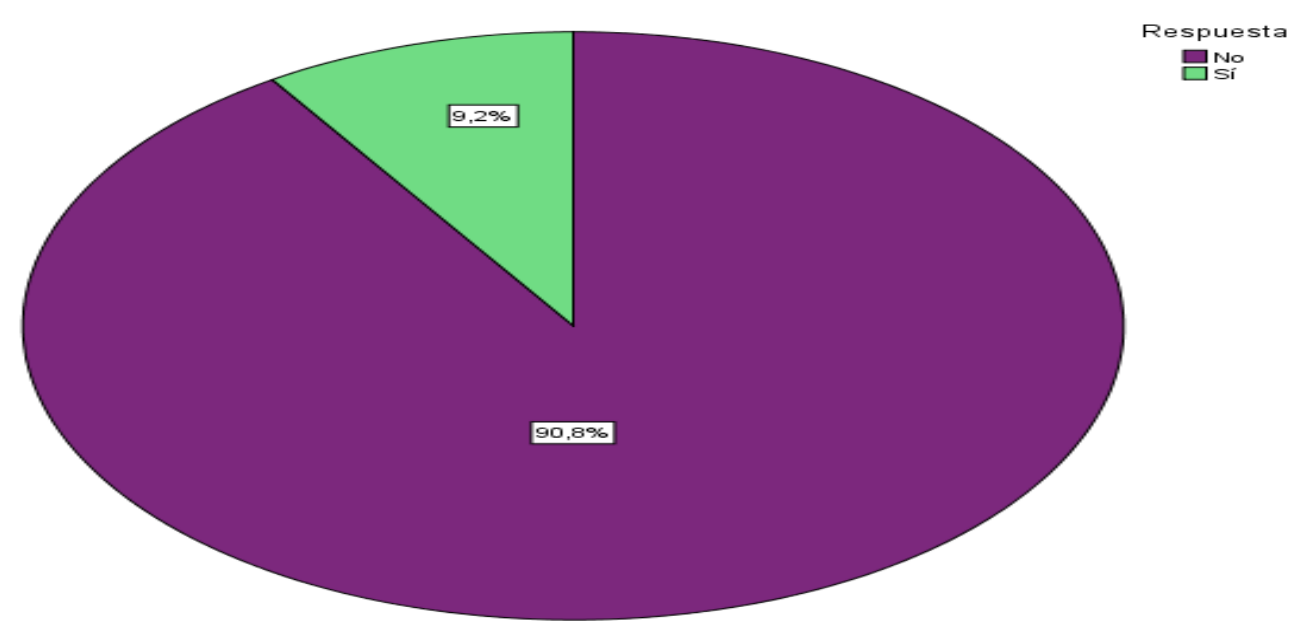

Figura 3. Distribución de respuesta del alumnado respecto a la experiencia con la realización de este tipo de tarea teniendo en cuenta una escala constituida por las categorías muy buena, buena, mala y muy mala

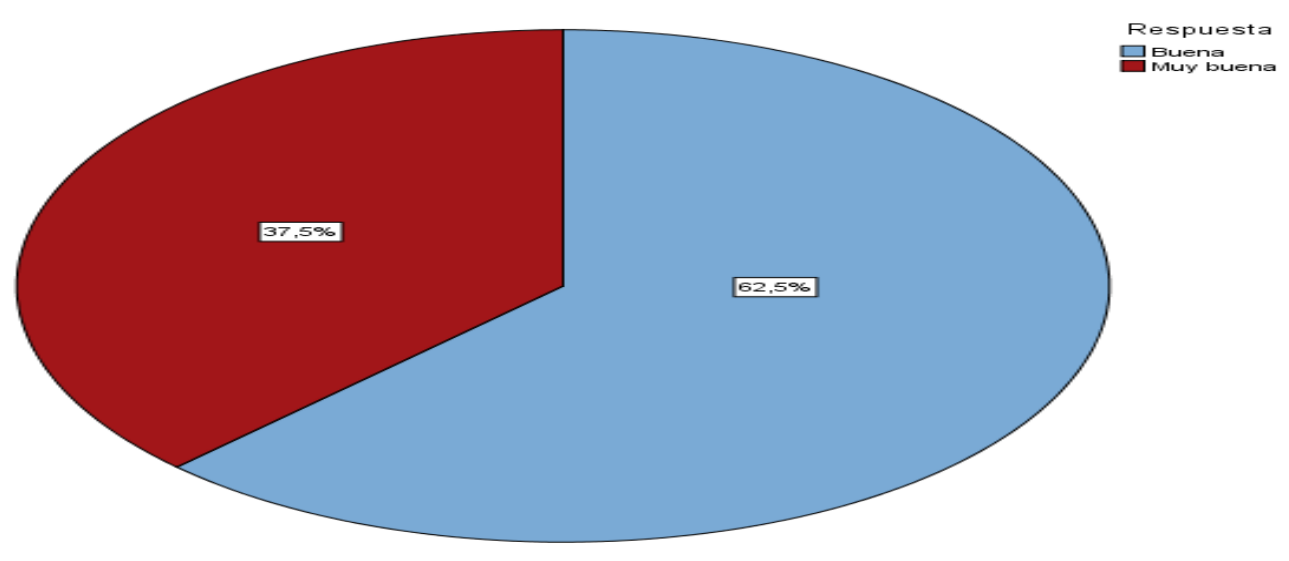

\section{Discusión}

La puesta en marcha de este proyecto ha permitido aprovechar las posibilidades tecnológicas y el uso de las TICs en el contexto universitario, dando la posibilidad al alumnado de acercarse a los contenidos (teóricos y prácticos) de una asignatura de manera innovadora sin hacer uso del tradicional "papel y lápiz". De esta forma, la elaboración y construcción por parte del alumnado del material didáctico audiovisual, utilizando los recursos multimedia con la tutorización y seguimiento del profesorado, ha permitido que el alumnado adquiera su propio proceso de aprendizaje de forma activa y autónoma facilitando una adquisición y desarrollo de competencias genéricas y transversales realista, útil y ajustada a los resultados de aprendizaje previstos en la asignatura.

En suma, las valoraciones realizadas por los propios estudiantes respecto al alcance e idoneidad de este tipo de propuesta muestran datos que pueden confirmar que la introducción y promoción del uso de este tipo de recursos en el aula representan 
medios útiles, interesantes y motivantes para potenciar su aprendizaje a nivel competencial. Así, este tipo de propuestas pueden proveer al profesorado universitario de herramientas metodológicas que faciliten la adopción de actuaciones docentes adaptadas a nuestro sistema de educación superior en el que el protagonismo del alumno es clave en la construcción de su aprendizaje. Es importante también, como el propio alumnado considera, el papel de guía realizado por el propio docente que debe apoyarle en su aprendizaje. En este sentido, tal y como determina Perrenoud (2009), el enfoque por competencias es un modelo que da sentido al trabajo educativo. Para este autor es necesario situar al alumno en situaciones o problemas reales, e ir más allá del hecho de simplemente plantear ejercicios interesantes o ajustados. Es conveniente plantear situaciones pedagógicas que sean realmente productivas para el alumno, y le permitan enfrentarse a un proceso de aprendizaje progresivo, viable y necesario. Las PILFORCOMS representan un medio adecuado para crear este tipo de situaciones considerando las competencias específicas de una asignatura determinada, y yendo incluso más allá de lo que a nivel teórico puede aportar lo que conocemos como las píldoras educativas.

Por tanto, la propuesta presentada representa la posibilidad de idear y desarrollar medios que permitan optimizar los procesos de enseñanza-aprendizaje, ofreciendo herramientas que incidan en un aprendizaje aplicado que acerque mucho más al estudiante de forma novedosa al perfil profesional con el que deben contar de cara a su futuro laboral dentro de su área de conocimiento específica.

Una vez puesta en marcha la propuesta y analizado los resultados obtenidos, podemos observar que se confirman y fundamentan las siguientes conclusiones:

- Las píldoras formativas competenciales son herramientas didácticas novedosas que se ajustan a la realidad educativa del momento y permiten una adquisición del aprendizaje de forma constructiva, significativa y activa por parte del alumnado, además de ser un tipo de aprendizaje competencial. La necesidad de proveer a las asignaturas de medios que optimicen la construcción del conocimiento por parte del alumnado de manera autónoma, facilitando la adquisición de las competencias asociadas a una asignatura en cuestión, hacen que este tipo de iniciativas sean adecuadas y claramente viables.

- Su funcionalidad puede ser posible gracias a las facilidades que nos ofrecen los recursos tecnológicos con los que contamos en la actualidad, confirmándose además en el proyecto que el manejo de estos recursos no suponen una dificultad añadida para los estudiantes. De hecho, la irrupción de las TICs en el contexto educativo pueden proveer al profesorado de mayores posibilidades técnicas y metodológicas que le permitan poner en marcha experiencias como las planteadas en este proyecto.

- Ofrecen múltiples posibilidades formativas y pueden ser aplicadas en prácticamente cualquier asignatura. En este sentido, pueden convertirse en un recurso práctico para que el alumnado pueda profundizar en el trabajo de las competencias asociadas a un estudio de grado, en cualquier modalidad o área de conocimiento, haciéndolas un elemento de interés a nivel educativo que puede aproximar al estudiante al perfil profesional con el que debe contar en su futuro profesional.

\section{Referencias}

Bengochea, L. y Medina, J.A. (2013). El papel de los vidiotutoriales accesibles en el aprendizaje del futuro. Actas del V Congreso Internacional ATICA, Huancayo, Perú. Recuperado en julio de 2016 de http://www.esvial.org/wpcontent/files/Videotutoriales BengocheaMedina.pdf 
Carrera, F. (2011). Knowledge pills methodology applied to small and medium-size enterprises. Recuperado en julio de 2016 de archive.is/www.edupills.eu

Carrera, F. (2012). Metodología de las píldoras de conocimiento. Manual del mediador de conocimiento. http://www.juntadeandalucia.es/institutodeadministracionpublica/aplicaciones/boletin/publico/boletin67/Articulos _67/Manual_metodologia_pildoras_conocimiento(RPIAAP_2012).pdf

Delgado, V. y Ruiz, M. (2014). Creación de píldoras formativas audiovisuales mediante la técnica de animación cut-out. En A. Mendieta (Coord.). Visiones docentes en las aulas de hoy, pp. 149-174. Madrid: ACCI.

Dorado, C. (2008). Estrategias de enseñanza-aprendizaje y modelos en entornos de e-learning. Revista de didáctica, 3 , 103-126.

Estévez, R. y, González, C.S. (2014). El objeto de aprendizaje audiovisual: un estudio cuasi- experimental sobre su valor pedagógico, V Jornadas Internacionales de Campus Virtuales, At Ciudad de Panamá, Panamá.

Goodyear, P., y Steeples, C. (1998). Creating shareable representations of practice. Association for Learning Technology Journal, 6(3), 16-23.

León, C., González, I., López, A.B., y López, I. (2012). INVADIV. Un modelo docente para la formación en competencias educativas. I Congreso Virtual Internacional sobre Innovación Pedagógica y Práxis Educativa. INNOVAGOGIA. Libro de Actas, 21, 22 y 23 de Noviembre.

Mayer, R. E. (2001). Multimedia learning (2 ${ }^{\text {nd }}$. Ed.). New York: Cambridge University Press

Mayer, R. (2002). Cognitive Theory and the Design of Multimedia Instruction: An Example of the Two-Way Street Between Cognition and Instruction. New directions for teaching and learning, 89, 55-71. Recuperado en julio de 2016 de www.fp.ucalgary.ca/maclachlan/cognitive_theory_mm_design.pdf

Mayer, R. (2010). Aprendizaje e instrucción. Madrid: Alianza.

Moreno, R. y, Mayer, R. E. (1999). A Cognitive Theory of Multimedia Learning: The role of modality and contiguity, Journal of Educational Psychology, 91 (2), 358-368.

Perrenoud, P. (2009). Enfoque por competencias. ¿Una respuesta al fracaso escolar? Revista Interuniversitaria de Pedagogía Social, 16, 45-64.

Santana Vega, L.E. y Santana Lorenzo, A. (2011). Las TIC, una herramienta para la orientación educativa y profesional de los jóvenes. En González González, C.S. (Dir.), Nuevas Tendencias en TIC y Educación, Vol. 1, pp. 72-83. Bubok.

Schnotz, W. (2002). Aprendizaje multimedia desde una perspectiva cognitiva, Revista de Docencia Univesitaria, 2(2), texto en línea, Recuperado en julio de 2016 de http://revistas.um.es/redu/article/view/20011/19381

Shepard, R.N., y Cooper, L.A. (1982). Mental images and their transformations. Cambridge, MA: MIT Press.

Sorden, S. (2013). Cognitive theory of multimedia learning. In B. J. Irby, G. Brown, R. Lara-Alecio, and S. Jackson (Eds.). The Handbook of Educational Theories, pp. 155-168. Charlotte, NC: Information Age.

Universidad de Vigo (s.f.). Manual para la grabación de píldoras educativas. Recuperado de http://wiki.media.uvigo.es/download/attachments/327707/manual_pildoras_polimedia.pdf

Whatley, J. y Ahmad, A. (2007). Using Video to Record Summary Lectures to Aid Students' Revision, Interdisciplinary Journal of Knowledge and Learning Objects, 3, 185-196.

Young, C. y Asensio, M. (2002). Looking through three "I"s: The pedagogic use of streaming video. Third International Conference of Networked Learning, Sheffield, March 2002. 